\title{
Bicuspid aortic valve surgery with proactive ascending aorta repair
}

\author{
Lars G. Svensson, MD, PhD, ${ }^{\mathrm{a}, \mathrm{b}}$ Kyung-Hwan Kim, MD, ${ }^{\mathrm{a}}$ Eugene H. Blackstone, MD, ${ }^{\mathrm{a}, \mathrm{d}}$ \\ Jeevanantham Rajeswaran, MSc, ${ }^{\mathrm{d}}$ A. Marc Gillinov, MD, ${ }^{\mathrm{a}}$ Tomislav Mihaljevic, MD, ${ }^{\mathrm{a}}$ \\ Brian P. Griffin, MD,${ }^{c}$ Richard Grimm, DO, ${ }^{c}$ William J. Stewart, MD, ${ }^{c}$ Donald F. Hammer, MD, ${ }^{c}$ and \\ Bruce W. Lytle, MD ${ }^{\mathrm{a}, \mathrm{b}}$
}

Objectives: Bicuspid aortic valves are associated with aortic catastrophes, particularly dissection. We examined
whether proactive repair of associated dilatation would reduce risk of subsequent aortic dissection or reoperation
and whether more aggressive resection is needed in patients undergoing bicuspid aortic valve surgery alone.

\begin{abstract}
Methods: From January 1993 to June 2003, 1989 patients (of our total experience of 4316) underwent bicuspid aortic valve surgery. Long-term outcomes of 1810 were analyzed according to aortic size and whether bicuspid aortic valve surgery was performed alone or with aortic repair.

Results: In-hospital 30-day survival was similar (98.8\% valve alone vs $98.9 \%$ with aortic repair), with no penalty incurred for concomitant aortic repair. Bicuspid aortic valve-alone patients had worse late survival $(75 \% \mathrm{vs} 85 \%$ at 10 years, $P=.0001)$, but in the matched cohort survival was nearly identical $(85 \%$ vs $86 \% ; P=.7)$. With this strategy, freedom from late aortic events was high in both groups $(99 \%$ valve alone vs $97 \%$ with aortic repair at 10 years; $P[\log$-rank $]=.06)$ and similar in the matched cohort $(95 \%$ vs $97 \% ; P=.2)$. Approximately $95 \%$ of patients undergoing valve-alone surgery had aortic diameters smaller than $4.6 \mathrm{~cm}$ or cross-sectional area/height ratios less than $9.4 \mathrm{~cm}^{2} / \mathrm{m} ; 80 \%$ undergoing valve surgery plus aortic repair had diameters larger than $4.1 \mathrm{~cm}$ or ratios greater than $7.3 \mathrm{~cm}^{2} / \mathrm{m}$. Only $0.2 \%$ of events occurred at an aortic diameter size of less than $4.5 \mathrm{~cm}$.
\end{abstract}

Conclusions: Aortic size larger than $4.5 \mathrm{~cm}$ or aortic cross-sectional area/height ratio greater than 8 to 10 should be considered triggers for concurrent aortic repair, because there is no added risk, and late survival is better; however, more aggressive resection is unwarranted. (J Thorac Cardiovasc Surg 2011;142:622-9)

Supplemental material is available online.

Bicuspid aortic valves are present in $1 \%$ to $2 \%$ of the population and are associated with aortic valve stenosis and regurgitation, resulting heart failure, valve surgery at an earlier age than in those with tricuspid valves, and such aortic problems as coarctation of the aorta, ascending

From the Department of Thoracic and Cardiovascular Surgery, ${ }^{a}$ Heart and Vascular Institute; the Aortic Surgery Center, ${ }^{\mathrm{b}}$ Heart and Vascular Institute; the Department of Cardiovascular Medicine, ${ }^{\mathrm{c}}$ Heart and Vascular Institute; and the Department of Quantitative Health Sciences, ${ }^{\mathrm{d}}$ Research Institute, Cleveland Clinic, Cleveland, Ohio.

Supported in part by the Kenneth Gee and Paula Shaw, PhD, Chair in Heart Research (to E.H.B), the Judith Dion Pyle Chair in Heart Valve Research (to A.M.G.), the Donna and Ken Lewis Chair in Cardiothoracic Surgery and Peter Boyle Research Fund (to T.M.), and the John and Rosemary Brown Endowed Chair in Cardiovascular Medicine (to B.P.G.).

Disclosures: A.M.G. receives compensation from Edwards Lifesciences (consultant, speakers bureau, significant) and from St Jude Medical (research support, significant, and speakers bureau, modest). T.M. receives compensation from Edwards Lifesciences (consultant) and from Intuitive Surgical (consultant, recipient of speaker fees).

Received for publication Feb 25, 2010; revisions received Sept 22, 2010; accepted for publication Oct 24, 2010; available ahead of print Feb 4, 2011.

Address for reprints: Lars G. Svensson, MD, PhD, Department of Thoracic and Cardiovascular Surgery, Cleveland Clinic, 9500 Euclid Ave, Desk J4-1, Cleveland, OH 44195 (E-mail: svenssl@ccf.org).

0022-5223/\$36.00

Copyright (c) 2011 by The American Association for Thoracic Surgery doi:10.1016/j.jtcvs.2010.10.050 aortic aneurysm, and aortic dissection. ${ }^{1-8}$ Aortic dissection, particularly in patients with bicuspid valves, carries a high risk of immediate death and death during emergency surgery and is associated with considerably reduced late survival. ${ }^{1,7,9}$ Of those patients with acute dissection, $15 \%$ have bicuspid aortic valves. ${ }^{7}$ Among patients with bicuspid aortic valves, aortic dissection occurs in $12 \%$ with aortic diameter smaller than $5.0 \mathrm{~cm},{ }^{9}$ which is similar to the $15 \%$ prevalence seen among patients with Marfan syndrome with aortic diameter smaller than $5.0 \mathrm{~cm} .{ }^{10}$ Indeed, when the ratio of aortic cross-sectional area (square centimeters) divided by height (meters) is greater than 10, risk of dissection increases for both groups. ${ }^{9,10}$ Furthermore, shorter patients are more prone to dissection at an equivalent aortic size. ${ }^{9,10}$ Timing of surgery and procedures continues to be debated, with some authors advocating surgery at an aortic size larger than $5.5 \mathrm{~cm}$ and others at smaller than $4.5 \mathrm{~cm} .{ }^{9-19}$

The aims of this study were as follows: (1) to identify differences between patients undergoing bicuspid aortic valve surgery alone and those for whom concomitant ascending aortic repair was performed, with particular emphasis on determining whether various methods of indexing aortic valve size to body size might differentiate these groups of patients, and (2) to evaluate early and late risk-adjusted outcomes of patients undergoing bicuspid aortic valve surgery with or without a proactive approach to repairing the 


\section{Abbreviations and Acronyms \\ $\mathrm{CI}=$ confidence interval \\ $\mathrm{CT}=$ computed tomography \\ MRI = magnetic resonance imaging}

ascending aorta. Specifically, we examined whether concomitant repair of the ascending aorta can be done safely, whether aortic dimensions matter, how this approach influences late outcome, and whether even more aggressive surgery is needed.

\section{MATERIALS AND METHODS}

From January 1993 to June 2003, 1989 patients underwent bicuspid aortic valve surgery at Cleveland Clinic (our total experience with bicuspid aortic valves is 4316 patients, of whom 771 underwent repair); among them, 1810 preoperative echocardiograms suitable for ascending aorta measurement were available (echocardiograms in which the ascending aorta was not adequately imaged were excluded). This interval was chosen to allow long-term follow-up and also because during this period indications for concomitant aortic resection were not clearly defined, and thus there was greater heterogeneity in resecting the aorta according to size. Among the $1810 \mathrm{pa}-$ tients with suitable echocardiograms, $1449(80 \%)$ had bicuspid aortic valve surgery alone (valve-alone group), and 361 (20\%) had bicuspid aortic valve surgery plus concomitant ascending aortic repair (valve-aorta group). Ascending aortic procedures performed included composite valve tube graft in 208 cases, ascending aorta tube graft in 117, and root procedure plus aortic valve repair in 36. During this time, 245 patients had bicuspid aortic valves repaired. Since then, however, the proportion of patients undergoing repair has increased because of improved techniques and results. ${ }^{1,3,4,15}$ Mean age in the valve-alone group was $56 \pm 15$ years (range, $18-90$ years), and $76 \%$ were men; in the valve-aorta group, mean age was $54 \pm 14$ years (range, 20-86 years), and 82\% were men (Table E1).

Patient and procedure variables were entered prospectively into the Cleveland Clinic Cardiovascular Information Registry. Use of these registry data for research was approved by the Institutional Review Board, with patient consent waived.

\section{Echocardiographic Measurements}

In the preoperative parasternal long-axis transthoracic echocardiographic view, the ascending aorta was measured 1 to $2 \mathrm{~cm}$ above the sinotubular junction. All echocardiograms were reviewed and measured by one of us (K.-H.K.). We were interested to see whether various methods of indexing aortic size to height or body surface area might differentiate between patients who had undergone valve-alone versus combined valve-aorta operations (Table 1). Size of the ascending aorta was analyzed in 3 ways. The first was simply its diameter, as measured echocardiographically. The second normalized the diameter and circularized area (in square centimeters) derived from this to patient height. ${ }^{9,10}$ The third standardized the degree of normality of ascending aorta dimension according to the body surface area of the patient. This was expressed as a $Z$ value, the number of SDs that the patient's aortic diameter deviated from mean normal dimension ( $95 \%$ of normal individuals are within -2 and $+2 \mathrm{Z}$ units). Other expressions were also examined (Table E2). Routine transesophageal echocardiography was done intraoperatively.

Computed tomography. Computed tomography (CT) and magnetic resonance imaging (MRI) were done only for patients with suspected aortic aneurysm. These data were therefore not available for all patients in this study. Nevertheless, echocardiographic imaging was available for most of the ascending aorta and aortic root and was routinely recorded, as described in the preceding text. Among patients who had aneurysms, most underwent further imaging by CT or MRI; if aneurysms were not significantly enlarged on echocardiography, however, further imaging may not have been performed. We therefore used echocardiography for preoperative assessment. CT or MRI would have shown any arch or descending aorta involvement or coarctation. Because this was a retrospective study and patients were followed by referring physicians, routine late CT or MRI studies were not performed.

Surgery. Valve-alone procedures were performed on the basis of patient symptoms or evidence of left ventricular deterioration. If the predominant lesion was aortic valve regurgitation, then the valve was evaluated for possible repair according to a Commissure, Leaflet, Annulus, Sinuses, Sinotubular (CLASS) schema. ${ }^{3,15}$ The decision to perform combined valve and aorta resection was based on aortic size and the quality of each patient's aorta. The quality of the aorta was subjectively assessed by surgeons based on wall thickness, ability to hold sutures, and whether a potential dissection plane was visible in the media. During this period, the approach to repair the aorta was heterogeneous and was based on the judgment of the surgeon. This gives strength to the study in that no specific cutoff point was used. Although many patients had ascending aorta tube grafts, if the root was enlarged substantially, a composite valve graft was inserted or an aortic root remodeling or modified David reimplantation procedure was performed. ${ }^{3,4,8,13,15}$ A minimally invasive incision was preferred for both valve-alone and combined valve-aorta repairs. The typical repair technique for bicuspid valves was placement of Cabrol sutures at the commissures, plication of clefts, release of raphe, and leading-edge figure-of- 8 sutures, as described previously. ${ }^{15}$

\section{Outcomes}

Outcomes considered were in-hospital mortality, long-term events related to the ascending aorta, and long-term all-cause mortality. Patients were followed up systematically at 2-year intervals, supplemented by a cross-sectional follow-up by Institutional Review Board-approved mailed questionnaire or telephone interview requiring patient consent, with emphasis on assessing events related to the aorta, including ascertaining mode of death. Mean follow-up was $5.9 \pm 3.6$ years for the valve-alone group and $6.7 \pm 3.6$ years for the valve-aorta group, with $10 \%$ followed up longer than 11 years; 8550 and 2411 patient-years of data were available for analysis, respectively. Data on vital status were augmented with the Social Security Death Index, ${ }^{20,21}$ yielding mean follow-up for vital status of 9.2 \pm 4.0 years for the valve-alone group and $9.0 \pm 3.4$ years for the valve-aorta group. Seventy-five patients $(4.1 \%)$ were unavailable for follow-up, and all were checked for death with the Social Security Death Index.

\section{Data Analysis}

Differences between valve-alone and valve-aorta patients. Data analysis first addressed dissimilarities between the valve-alone and valve-aorta groups (Table E1), so that comparisons of outcome were fair. Briefly, multivariable logistic regression analysis was used to identify a parsimonious set of patient and procedure variables associated with combined valve and aorta surgery versus valve surgery alone. Bagging was used for variable selection (see Appendix for variables considered), ${ }^{22}$ with automated analysis of 1000 bootstrap samples and a $P$ value for retention of .05. Frequency of occurrence of individual factors or clusters of highly correlated factors in these analyses was counted (aggregation step), and factors appearing in $50 \%$ or more of the analyses were considered reliably statistically significant at $P \leq .05$. To this parsimonious model were added nonsignificant variables representing groups of patient, coronary disease, valve pathology, and surgical procedure variables that might be related to unrecorded selection factors (saturated propensity model). ${ }^{23}$ Because preoperative diagnostic aneurysm and dilated aorta variables act as surrogates for group membership, they were not included in the 
TABLE 1. Factors associated with higher likelihood of undergoing bicuspid aortic valve surgery and ascending aorta repair

\begin{tabular}{|c|c|c|c|}
\hline Factor & Estimate \pm SE & $\boldsymbol{P}$ & Reliability $(\%)^{*}$ \\
\hline $\begin{array}{l}\text { Larger ascending aorta } \\
\text { diameter } \dagger\end{array}$ & $-21 \pm 1.3$ & $<.0001$ & 100 \\
\hline Emergency operation & $1.9 \pm 0.59$ & .001 & 77 \\
\hline No LCx disease & $-0.63 \pm 0.19$ & .0008 & 95 \\
\hline Lower AV stenosis grade & $-0.15 \pm 0.033$ & $<.0001$ & 87 \\
\hline Nonsevere LV dysfunction $\ddagger$ & $-0.023 \pm 0.010$ & .02 & 54 \\
\hline $\begin{array}{l}\text { More recent date of } \\
\text { operation }\end{array}$ & $0.13 \pm 0.029$ & $<.0001$ & 93 \\
\hline
\end{tabular}

$A V$, Aortic valve; $L C x$, left circumflex; $L V$, left ventricular; $S E$, standard error. *Percentage of times factor appeared in 1000 bootstrap models. $\dagger($ Height/diameter), inverse transformation. Ascending aortia diameter normalized by patient height. $\ddagger(\mathrm{LV} \text { dysfunction grade })^{2}$, squared transformation.

propensity model. Using this saturated model, a propensity score was calculated for each patient $(\mathrm{C}=.90)$.

Propensity matching. Using only the propensity score, patients from the valve-aorta group were matched 1:1 with patients from the valve-alone group with a greedy matching strategy. Patients in the valve-aorta group whose propensity scores deviated more than approximately 0.2 from those of patients in the valve-alone group were considered unmatched; 206 wellmatched pairs $(57 \%)$ were obtained.

Comparison of early outcomes. Because there were few inhospital deaths or strokes, we performed focused logistic regression analysis with treatment group and ascending aorta size variables included in the model, along with propensity score, as covariables for risk adjustment. ${ }^{24}$

Comparison of time-related outcomes. Freedom from longterm events related to the ascending aorta and survival estimates were obtained using the Kaplan-Meier nonparametric method. A parametric method was used to resolve the number of phases of instantaneous risk (hazard function) and to estimate shaping parameters. ${ }^{25}$ (For additional details, see http://my.clevelandclinic.org/professionals/software/hazards/ default.aspx.) Because this was a retrospective study, patients who had valvular disease alone would have been followed up only by echocardiography unless there was evidence of aneurysmal formation. Longitudinal CT or MRI data were therefore not available for following any potential aortic growth other than those detected by echocardiography or incidental CT or MRI that in turn resulted in referral for reoperation.

\section{Data Presentation}

Continuous variables are summarized as mean $\pm \mathrm{SD}$, or equivalently as 15th, 50th, (median), and 85th percentiles when the distribution of values was skewed. Categoric variables are summarized as frequencies and percentages. Continuous variables were compared using the Wilcoxon ranksum test. Categoric variables were compared using the $\chi^{2}$ test when the smallest number of individuals in a category was more than 5 and with Fisher's exact test otherwise. Freedom from events related to ascending aorta and survival estimates are accompanied by asymmetric $68 \%$ confidence limits, equivalent to $\pm 1 \mathrm{SE}$.

\section{RESULTS}

\section{Differences Between Valve-Alone and Valve-Aorta Patients}

Patients in the valve-aorta group were more likely than those in the valve-alone group to undergo emergency surgery and were less likely to have circumflex coronary
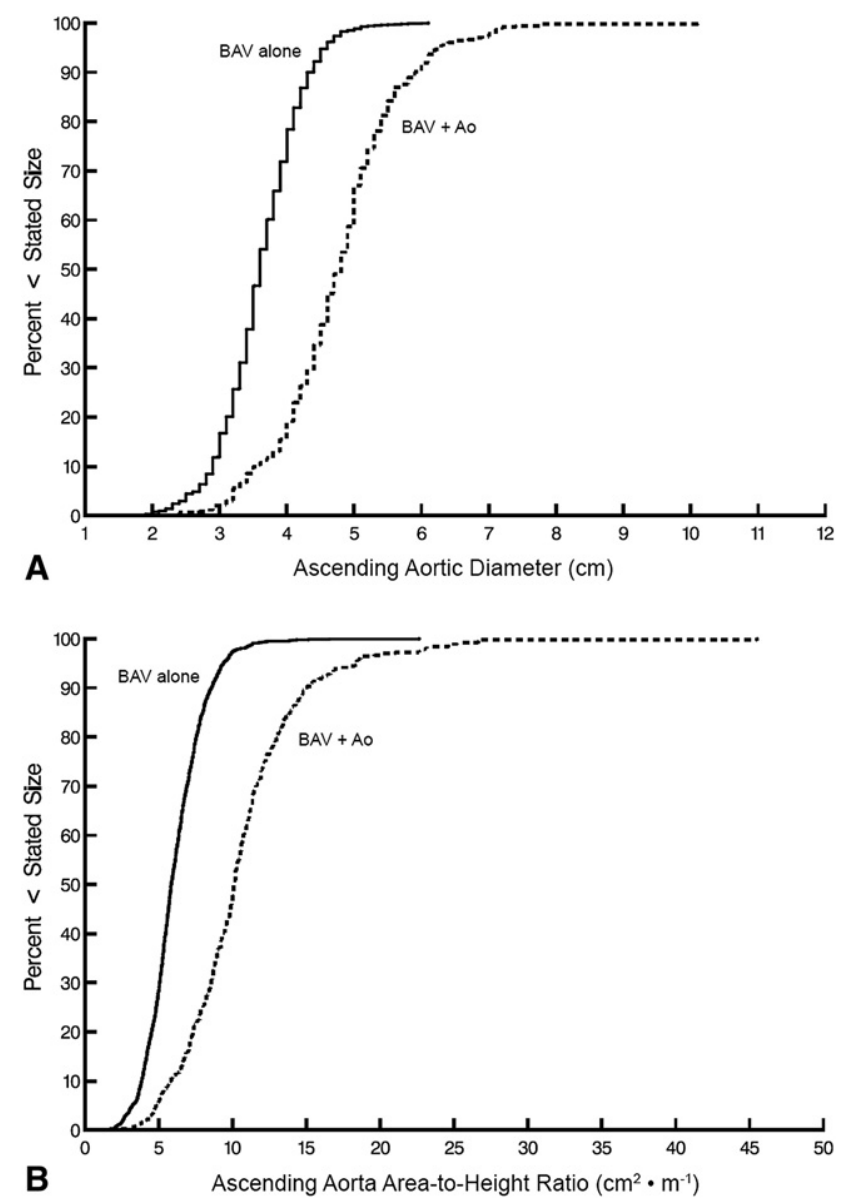

FIGURE 1. Cumulative distribution of ascending aorta size at bicuspid aortic valve surgery. Vertical axis represents nonparametric percentile; thus, the value for ascending aorta diameter at the $50 \%$ point on the vertical axis is the median value (50th percentile), the values at $10 \%$ and $90 \%$ are the 10th and 90th percentiles, and so forth. A, Diameter. B, Area/height ratio. $B A V$, Bicuspid aortic valve surgery alone; $B A V+A o$, bicuspid aortic valve surgery and ascending aorta repair.

artery disease, aortic valve stenosis, or left ventricular dysfunction. They were operated on more frequently and had larger aortic diameters (with similar C-statistics for aortic diameter or area normalized to height $[\mathrm{C}=.86]$ or standardized to $\mathrm{Z}$ value $[\mathrm{C}=.85]$; Table 1 ).

Heterogeneity of decision making resulted in wide overlap of ascending aorta size, however expressed (Figure 1, Table E2). Nevertheless, patients with aortic diameters larger than $4.2 \mathrm{~cm}$ frequently underwent aortic replacement (Figure 1, A), and at approximately $4.7 \mathrm{~cm}, 100 \%$ had replacement. Similarly, at an aortic cross-sectional area/ height ratio of 8 to $9 \mathrm{~cm}^{2} / \mathrm{m}$, the aorta was increasingly replaced; at a value of 10 , virtually all patients underwent aortic replacement (Figure $1, B$ ). Above a $\mathrm{Z}$ value of +5 , the aorta was increasingly replaced; above +8 , nearly $100 \%$ were replaced (Figure E1). 


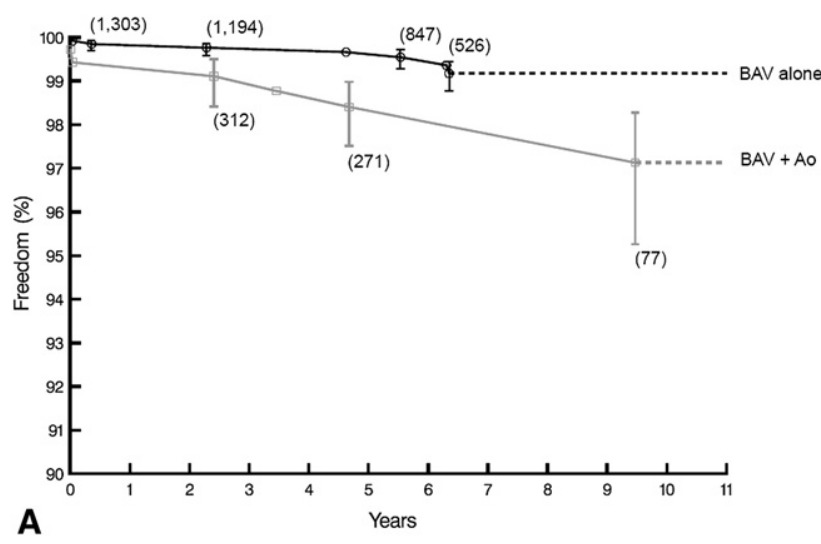

Valve-alone group $(\mathrm{n}=1449)$ events were (1) 1 reoperation for aortic dissection at 14 days, (2) 1 death from aortic dissection 4.1 months after the patient refused reoperation, (3) 1 dissection reoperated 2.3 years after surgery, (4) 1 distal aortic aneurysm at 4.6 years, (5) 1 reoperation for ascending aorta aneurysm at 5.5 years, (6) 1 root aneurysm at 6.3 years, (7) 1 root aneurysm at 6.4 years, and (8) 1 dilated ascending aorta at 11.5 years. Aortic diameters, cross-sectional area/ height ratios, and $\mathrm{Z}$ values before surgery were $4.6 \mathrm{~cm}, 5.2$ $\mathrm{cm}, 4.0 \mathrm{~cm}, 4.8 \mathrm{~cm}, 4.7 \mathrm{~cm}, 3.1 \mathrm{~cm}, 6.0 \mathrm{~cm}$, and $4.2 \mathrm{~cm}$; $9.1 \mathrm{~cm}^{2} / \mathrm{m}, 14 \mathrm{~cm}^{2} / \mathrm{m}, 7.0 \mathrm{~cm}^{2} / \mathrm{m}, 9.7 \mathrm{~cm}^{2} / \mathrm{m}, 9.9 \mathrm{~cm}^{2} / \mathrm{m}$, $4.8 \mathrm{~cm}^{2} / \mathrm{m}, 16 \mathrm{~cm}^{2} / \mathrm{m}$, and $7.8 \mathrm{~cm}^{2} / \mathrm{m}$; and $6.4,9.0,5.3$, $6.1,6.5,3.7,9.4$, and $6.1 \mathrm{Z}$, respectively. Thus, for the valve-alone group, nonparametric Kaplan-Meier estimates of freedom from aortic events at 1,5 , and 10 years were, respectively, $99.8 \%, 99.7 \%$, and $99 \%$. Of note, only 3 of 1449 patients $(0.2 \%)$ in the valve-alone group had aortic events after operation at an aortic diameter smaller than $4.5 \mathrm{~cm}$.

In the valve-aorta group $(\mathrm{n}=361)$, aortic events were (1) 1 death from aortic dissection at 2 days, (2) 1 death from dissection beyond an allograft 14 days after surgery, (3) 1 reoperation for root aneurysm 2.4 years later, (4) 1 reoperation for root aneurysm 3.5 years later, (5) 1 reoperation for root aneurysm 4.7 years later, and (6) 1 reoperation for dilated aorta 9.5 years later. Aortic diameters, crosssectional area/height ratios, and $\mathrm{Z}$ values before surgery were $6.0 \mathrm{~cm}, 4.9 \mathrm{~cm}, 5.2 \mathrm{~cm}, 3.6 \mathrm{~cm}, 4.5 \mathrm{~cm}$, and $3.2 \mathrm{~cm}$; $15 \mathrm{~cm}^{2} / \mathrm{m}, 12 \mathrm{~cm}^{2} / \mathrm{m}, 13 \mathrm{~cm}^{2} / \mathrm{m}, 5.6 \mathrm{~cm}^{2} / \mathrm{m}, 8.8 \mathrm{~cm}^{2} / \mathrm{m}$, and $4.5 \mathrm{~cm}^{2} / \mathrm{m}$; and $8.5,9.1,8.6,4.1,5.9$, and $2.5 \mathrm{Z}$, respectively. Of note, only 3 patients developed a root aneurysm, and only 1 underwent reoperation for late arch aneurysm. Thus, for this latter group, nonparametric Kaplan-Meier estimates of freedom from aortic events at 1,5 , and 10 years were, respectively, $99.4 \%, 98.4 \%$, and $97.1 \%$. Riskunadjusted comparison shows that patients in the valveaorta group were somewhat more likely to have aortic events than were those in the valve-alone group $(P[\log -$ rank $]=.06$; Figure 2, $A$ ). Matched comparison, however, shows freedom from ascending aorta-related events to be similar $(P[\log -$ rank $]=.2$; Figure $2, B)$. Thus, based on the decision making described, reintervention on the aorta was rare for both groups. That is, later reoperation for aneurysm repair was rare for valve-alone procedures, and false aneurysms or late complications were also rare for combined valve-aorta procedures.

\section{Long-Term Survival}

Risk-unadjusted survival after combined valve-aorta procedures was better ( $85 \%$ 10-year survival) than after valve-alone surgery $\quad(75 \% \quad 10$-year survival, $P[\log$ rank] $=.0001$; Figures $3, A$, and E2), probably because of more severe symptoms in the valve-alone patients, associated with more severe aortic valve stenosis and worse left ventricular function (Tables 1 and E1). For the propensity-matched 

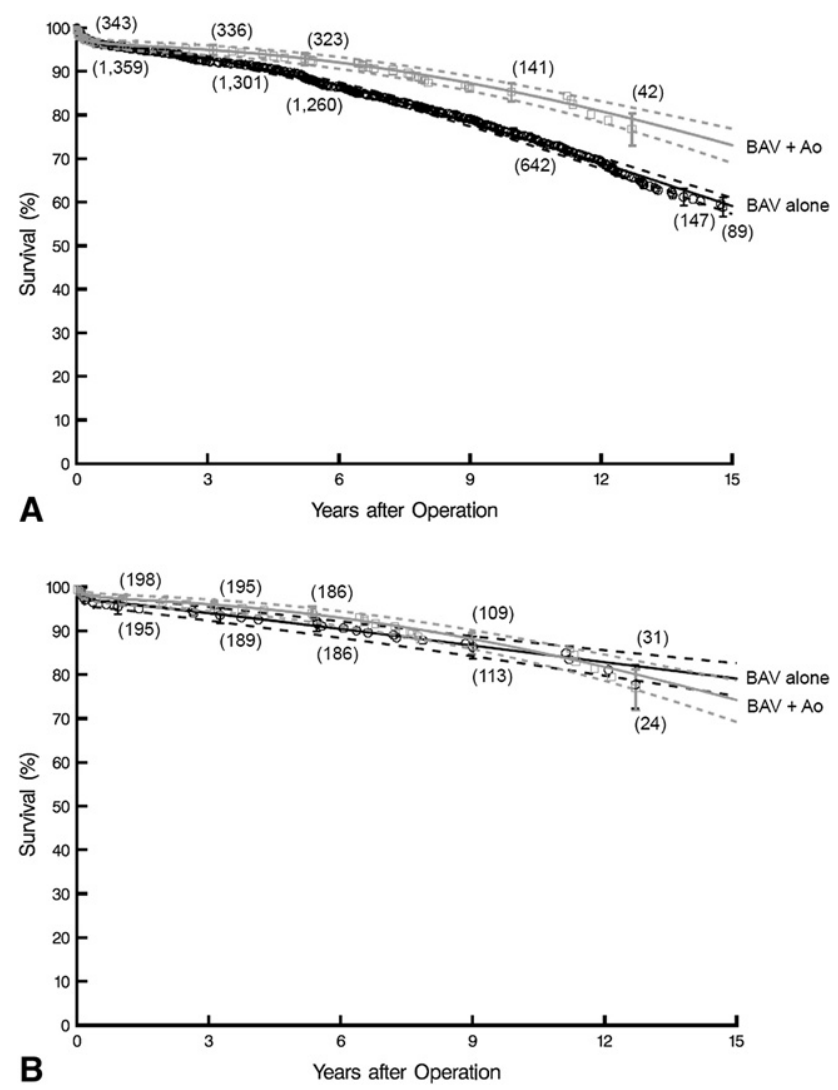

FIGURE 3. Survival for both groups. Format is as in Figure 2. Solid lines are parametric estimates enclosed within $68 \%$ confidence limits. A, Whole cohort. B, Matched cohort. $B A V$, Bicuspid aortic valve surgery alone (circles); $B A V+A o$, bicuspid aortic valve surgery and ascending aorta repair (squares).

cohort of 206 patients in each group, however, risk-adjusted survival was nearly identical (10-year survival $86 \%$ vs $85 \%$ and 15 -year survival $74 \%$ vs. $79 \%$, respectively, $P$ $[\log$-rank $]=.6$; Figure $3, B$ ), including for ventricular dysfunction. An important caveat is that propensity matching adjusted for preoperative symptoms, aortic valve disease, and ventricular dysfunction differences. There were no differences in survival or aortic complications according to repair or replacement of the valve, root procedure, or valve type (mechanical vs biologic).

\section{DISCUSSION \\ Principal Findings}

This study evaluated patients operated on during a period when no strict guidelines existed concerning when to resect the ascending aorta during bicuspid aortic valve procedures. Hence, there were some intersurgeon differences in the approach to management of a dilated aorta that resulted in a spectrum of procedures based on the initial diameter. Our results thus show that at an absolute diameter of 4.5 $\mathrm{cm}$ or greater or a cross-sectional area/height ratio higher than $8 \mathrm{~cm}^{2} / \mathrm{m}$, the aorta can be safely resected without added penalty. However, the recent trend of recommending more aggressive resection of the aorta when smaller than $4.5 \mathrm{~cm}$, or concurrently the aortic root, or electively the aortic arch, cannot be justified on the basis of this study. Indeed, only 1 patient with aortic diameter smaller than 4.5 $\mathrm{cm}$ required reoperation for aortic dissection. We therefore cannot justify the added risks of root resection with coronary reimplantation, or aortic arch resection with circulatory arrest and no concurrent significant aneurysmal dilatation beyond $4.5 \mathrm{~cm}$. Of interest, this study has also shown pari passu that patients operated on under current valve guidelines when they start to show symptoms or have developed left ventricular dysfunction have poorer late survival than less symptomatic patients (valve-aorta group). This raises the issue of whether severe bicuspid valve disease, as with mitral valve disease, should be addressed before development of symptoms or left ventricular dysfunction.

Bicuspid aortic valve is among the most common congenital cardiac defects. ${ }^{7}$ In this study, it was associated with aortic dilatation requiring proactive repair in $20 \%$ of patients. As the general population ages, aortic disease, including dissection and aneurysmal disease, is becoming more common, contributing to 43,000 to 47,000 deaths annually in the United States. ${ }^{6}$ Earlier treatment of aortic dilatation has therefore become paramount in preventing aortic dissection and aneurysmal complications.

We have for a number of years proactively and aggressively resected and repaired aortic dilatation associated with bicuspid valves, but not typically at diameters smaller than $4.5 \mathrm{~cm}$. In this study, every patient with an aortic diameter greater than $6.1 \mathrm{~cm}$ underwent repair. Indeed, $83 \%$ of those patients with a diameter greater than approximately $4.8 \mathrm{~cm}$ underwent repair (Figure 1, A). Similarly, we assessed aortic cross-sectional area/height ratio to indicate when surgery is required for a dilated aorta in patients with bicuspid valves or Marfan syndrome. ${ }^{9,10}$ We noted that approximately $95 \%$ of those who did not undergo an aortic procedure had a ratio less than $9.4 \mathrm{~cm}^{2} / \mathrm{m}$, whereas $80 \%$ of those who underwent ascending aortic repair had a ratio greater than $7.3 \mathrm{~cm}^{2} / \mathrm{m}$. Likewise, about $95 \%$ of patients who did not have an aortic procedure had a $\mathrm{Z}$ value less than 6.9 , whereas $80 \%$ of those who underwent ascending aortic repair had a $\mathrm{Z}$ value greater than 5.3.

Because the aorta increases in diameter with somatic growth, interpretation of measurements has been facilitated by normalizing it to height or body surface area (eg, indexed area, $\mathrm{Z}$ value). Indexing aortic size to these anthropomorphic data suggests that the cross-sectional area/height ratio discriminates rather well those patients who need concurrent aortic repair. Furthermore, this ratio also takes into account the greater risk of dissection in shorter patients. We encourage the use of this ratio for timing surgery in patients with bicuspid aortic valves or Marfan syndrome., ${ }^{9,10}$ 
Currently, for patients without symptoms, we use a ratio greater than $10 \mathrm{~cm}^{2} / \mathrm{m}$.

With this proactive approach, 10-year freedom from ascending aortic events was $97.1 \%$ for the valve-aorta group versus $99 \%$ for the valve-alone group, clearly a low risk. Indeed, when we saw these results, we rechecked all patients' late outcomes to ensure that no complication had been missed. Although we see patients from our larger experience who occasionally return for reoperation on either the aortic root or arch, this is uncommon unless aortic dissection was present at the index operation. Similarly, we see patients who have been operated on elsewhere; the denominator in this case is unknown, however, although with $1 \%$ to $2 \%$ of the population having bicuspid valves, it is likely large. Of note, in 2004, after the period of this study, Borger and colleagues ${ }^{1}$ recommended that ascending aorta replacement be used more often, because in their series 22 patients developed long-term complications related to the ascending aorta, particularly those in whom the aorta was greater than $4.5 \mathrm{~cm}$. Fifteen-year freedom from complications was $43 \%$, $81 \%$, and $86 \%$ for aortic diameters of 4.5 to $4.9 \mathrm{~cm}, 4.0$ to $4.5 \mathrm{~cm}$, and smaller than $4.0 \mathrm{~cm}$, respectively $(P<.001)$. Our study supports their hypothesis that proactive repair of the aorta, particularly when larger than $4.5 \mathrm{~cm}$ in diameter, reduces late risk of complications.

Reducing late complications related to aortic dilatation, however, would not be justified if doing so carried an increased early risk of death, stroke, or other serious complications related to surgery. We therefore used several methods, including propensity adjustment and propensity matching, to identify risk-adjusted differences in surgical risk between the groups. Despite this careful and detailed analysis, we found no statistically significant difference in early deaths or complications. Furthermore, the approximate $99 \%$ survival and $1.5 \%$ postoperative occurrence of stroke were gratifyingly good in both groups. There is thus no specific penalty (ie, increase in risk) associated with concomitant repair of the aorta.

On late follow-up, patients in the valve-aorta group had better non-risk-adjusted survival than did those in the valve-alone group. One likely explanation is that the valve-alone patients had more symptomatic aortic valve disease, either stenosis or regurgitation, resulting in symptoms as an indication for surgery, and worse left ventricular function (Tables 1 and E2). This raises the interesting issue of whether earlier surgery for significant but asymptomatic aortic valve disease might result in better long-term survival. Surgery should therefore be considered in young patients with severe valvular disease even if they show neither symptoms nor marked left ventricular dysfunction or dilatation. After propensity matching, the difference in long-term survival was not statistically significant for the 206 matched patient pairs. However, this propensity matching balanced symptoms, aortic stenosis or regurgitation, and left ventric- ular dysfunction and specifically addressed whether aortic repair affected survival. This matched analysis showed that addition of aortic repair did not negatively affect survival. Indeed, this would not be expected, unless perhaps related to a risk of false aneurysms or graft infection, but neither occurred. Current American College of Cardiology/American Heart Association guidelines for aortic valve surgery are essentially based on symptoms or measures of left ventricular dysfunction ${ }^{14}$; the issue of asymptomatic severe aortic valve disease and earlier surgery will need to be addressed during further guideline iterations.

\section{Limitations}

This was a clinical cohort study and not a randomized trial. A randomized trial would be difficult because of the continuous nature of aortic diameter. We did, however, use various methods to analyze the data and provide a fair comparison. We found no disadvantage to concomitant ascending aorta repair. Aortic diameter data were not collected prospectively; nevertheless, one of us (K.-H.K.) retrieved and reviewed every preoperative echocardiogram that did not give precise aortic diameters. Postoperative follow-up imaging of the aorta was not performed on a routine schedule with CT or MRI, and echocardiography was performed at the referring cardiologist's discretion.

\section{Recommendations}

Surgical options (based on 771 repairs) depend on the surgeon's experience, but in our opinion, a regurgitant bicuspid valve should be repaired, and if the ascending aorta is also significantly dilated (diameter larger than $4.5 \mathrm{~cm}$ or aortic cross-sectional area/height ratio greater than $10 \mathrm{~cm}^{2} / \mathrm{m}$ ), it should be replaced..$^{1-5,8,11,13-17,19}$ This study shows that failure to do so is associated with an increased risk of late aortic complications, particularly aortic dissection. If the root is enlarged, a remodeling root-sparing operation is preferred, because often these are young patients in whom biologic valves soon fail, and mechanical valves require lifelong anticoagulation., ${ }^{3,15,19}$ In our experience, 10year freedom from reoperation for bicuspid valve repair ranges from $79 \%$ to $83 \%$ for valve-alone procedures and is $91 \%$ for combined valve-aorta procedures, slightly less than for tricuspid valve repair and root-sparing or rootpreserving procedures $\left(96 \%\right.$ at 10 years). ${ }^{3,4,11,13,15,19}$ For patients with aortic valve stenosis, the valve will require replacement because attempted decalcification procedures fail within a few years.

Proactive aortic repair is recommended at the time of bicuspid aortic valve surgery when either the aortic diameter exceeds approximately $4.5 \mathrm{~cm}$, the aortic cross-sectional area/height ratio exceeds approximately 8 to $9 \mathrm{~cm}^{2} / \mathrm{m}$, or the $\mathrm{Z}$ value exceeds 7 . For patients with a bicuspid valve not requiring surgery, we recommend aortic repair when the aortic cross-sectional area/height ratio exceeds 10 
$\mathrm{cm}^{2} / \mathrm{m}$. Our data do not currently justify resecting the aorta if it is smaller than $4.5 \mathrm{~cm}$. Consideration should be given to stress testing patients with severe bicuspid valve disease before the development of symptoms or left ventricular dysfunction, because left ventricular mass exceeding $180 \mathrm{~g} / \mathrm{m}^{2}$ or a left atrium exceeding $4.5 \mathrm{~cm}$ may be better predictors of late survival than are symptoms. Furthermore, patients should be followed long term, preferably by MRI (to reduce the risks of CT-related radiation), for late development of aneurysm, particularly of the aortic arch. ${ }^{26}$

\section{References}

1. Borger MA, Preston M, Ivanov J, Fedak PW, Davierwala P, Armstrong S, et al. Should the ascending aorta be replaced more frequently in patients with bicuspid aortic valve disease? J Thorac Cardiovasc Surg. 2004;128:677-83.

2. Sundt TM III, Mora BN, Moon MR, Bailey MS, Pasque MK, Gay WA Jr. Options for repair of a bicuspid aortic valve and ascending aortic aneurysm. Ann Thorac Surg. 2000;69:1333-7.

3. Svensson LG, Blackstone EH, Cosgrove DM III. Surgical options in young adults with aortic valve disease. Curr Probl Cardiol. 2003;28:417-80.

4. Svensson LG, Blackstone EH, Feng J, de Oliveira D, Gillinov AM, Thamilarasan M, et al. Are Marfan syndrome and marfanoid patients distinguishable on long-term follow-up? Ann Thorac Surg. 2007;83:1067-74.

5. Svensson LG, Kim KH, Blackstone EH, Alster JM, McCarthy PM, Greenberg RK, et al. Elephant trunk procedure: newer indications and uses. Ann Thorac Surg. 2004;78:109-16.

6. Svensson LG, Rodriguez ER. Aortic organ disease epidemic, and why do balloons pop? Circulation. 2005;112:1082-4

7. Braverman AC, Güven H, Beardslee MA, Makan M, Kates AM, Moon MR. The bicuspid aortic valve. Curr Probl Cardiol. 2005;30:470-522.

8. Svensson LG. Sizing for modified David's reimplantation procedure. Ann Thorac Surg. 2003;76:1751-3.

9. Svensson LG, Kim KH, Lytle BW, Cosgrove DM. Relationship of aortic cross-sectional area to height ratio and the risk of aortic dissection in patients with bicuspid aortic valves. J Thorac Cardiovasc Surg. 2003;126:892-3.

10. Svensson LG, Khitin L. Aortic cross-sectional area/height ratio timing of aortic surgery in asymptomatic patients with Marfan syndrome. J Thorac Cardiovasc Surg. 2002;123:360-1.

11. Casselman FP, Gillinov AM, Akhrass R, Kasirajan V, Blackstone EH, Cosgrove DM. Intermediate-term durability of bicuspid aortic valve repair for prolapsing leaflet. Eur J Cardiothorac Surg. 1999;15:302-8.

12. Svensson LG, Labib SB, Eisenhauer AC, Butterly JR. Intimal tear without hematoma: an important variant of aortic dissection that can elude current imaging techniques. Circulation. 1999;99:1331-6.

13. Svensson LG, Longoria J, Kimmel WA, Nadolny E. Management of aortic valve disease during aortic surgery. Ann Thorac Surg. 2000;69:778-84.
14. Bonow RO, Carabello BA, et al, American College of Cardiology/American Heart Association Task Force on Practice Guidelines, Society of Cardiovascular Anesthesiologists, Society for Cardiovascular Angiography and Interventions, Society of Thoracic Surgeons. ACC/AHA 2006 guidelines for the management of patients with valvular heart disease: a report of the American College of Cardiology/American Heart Association Task Force on Practice Guidelines (writing committee to revise the 1998 Guidelines for the Management of Patients With Valvular Heart Disease): developed in collaboration with the Society of Cardiovascular Anesthesiologists: endorsed by the Society for Cardiovascular Angiography and Interventions and the Society of Thoracic Surgeons: developed in collaboration with the Society of Cardiovascular Anesthesiologists: endorsed by the Society for Cardiovascular Angiography and Interventions and the Society of Thoracic Surgeons. Circulation. 2006;114:e84-231.

15. Svensson LG, Deglurkar I, Ung J, Pettersson G, Gillinov AM, D’Agostino RS, et al. Aortic valve repair and root preservation by remodeling, reimplantation, and tailoring: technical aspects and early outcome. J Card Surg. 2007;22: 473-9.

16. Burkhart HM, Zehr KJ, Schaff HV, Daly RC, Dearani JA, Orszulak TA. Valvepreserving aortic root reconstruction: a comparison of techniques. J Heart Valve Dis. 2003;12:62-7.

17. Miller DC. Valve-sparing aortic root replacement in patients with the Marfan syndrome. J Thorac Cardiovasc Surg. 2003;125:773-8.

18. Svensson LG. Acute aortic syndromes: time to talk of many things. Cleveland Clin J Med. 2008;75:25-69.

19. Svensson LG, Crawford ES, Hess KR, Coselli JS, Safi HJ. Composite valve graft replacement of the proximal aorta: comparison of techniques in 348 patients. Ann Thorac Surg. 1992;54:427-39.

20. Boyle CA, Decouflé P. National sources of vital status information: extent of coverage and possible selectivity in reporting. Am J Epidemiol. 1990;131: $160-8$.

21. Newman TB, Brown AN. Use of commercial record linkage software and vital statistics to identify patient deaths. J Am Med Inform Assoc. 1997;4:233-7.

22. Breiman L. Bagging predictors. Machine Learning. 1996;24:123-40.

23. Blackstone EH. Comparing apples and oranges. J Thorac Cardiovasc Surg. 2002; 123:8-15.

24. Drake C, Fisher L. Prognostic models and the propensity score. Int J Epidemiol. 1995;24:183-7.

25. Blackstone EH, Naftel DC, Turner ME Jr. The decomposition of time-varying hazard into phases, each incorporating a separate stream of concomitant information. J Am Stat Assoc. 1986;81:615-24.

26. Hiratzka LF, Bakris GL, Beckman JA, Bersin RM, Carr VF, Casey DE Jr. et al. 2010 ACCF/AHA/AATS/ACR/ASA/SCA/SCAI/SIR/STS/SVM guidelines for the diagnosis and management of patients with Thoracic Aortic Disease: a report of the American College of Cardiology Foundation/American Heart Association Task Force on Practice Guidelines, American Association for Thoracic Surgery, American College of Radiology, American Stroke Association, Society of Cardiovascular Anesthesiologists, Society for Cardiovascular Angiography and Interventions, Society of Interventional Radiology, Society of Thoracic Surgeons, and Society for Vascular Medicine. Circulation. 2010; 121:e266-369. 


\section{APPENDIX. Variables Used in Propensity Model}

\section{Patient Variables}

Demography. Age (years), sex, ethnicity, weight (kilograms), height (centimeters), body surface area (square meters), body mass index (kilograms per square meter)

Symptoms. New York Heart Association functional class (I-IV), emergency operation

Ventricular dysfunction. Previous myocardial infarction, degree of left ventricular dysfunction (1, none; 2, mild; 3 , mild to moderate; 4 , moderate; 5 , moderately severe; 6 , severe)

Valve pathology. Aortic valve regurgitation, aortic valve stenosis, tricuspid valve regurgitation, mitral valve regurgitation

Ascending aorta. Diameter (centimeters) and its normalized and standardized derivatives (diameter/height [centimeters per meter], diameter/body surface area [centimeters per square meter], area [square centimeters], area/ height [square centimeters per meter], area/body mass index [square centimeters], area/body surface area [square centimeters per square meter], $\mathrm{Z}$ value)
Coronary anatomy. Left main trunk disease (percentage stenosis), left anterior descending coronary artery system disease (maximum percentage stenosis), right coronary artery system disease (maximum percentage stenosis), left circumflex coronary artery system disease (maximum percentage stenosis)

Other cardiac comorbidity. Atrial fibrillation, hypertension, history of cardiac disease, complete heart block/pacer, ventricular arrhythmia

Noncardiac comorbidity. Treated diabetes, insulintreated diabetes, history of endocarditis, history of peripheral arterial disease, history of smoking, carotid disease, popliteal disease, creatinine (milligrams per deciliter), blood urea nitrogen (milligrams per deciliter), bilirubin (milligrams per deciliter), creatinine clearance (milliliters per minute), hematocrit (percentage)

Experience. Date of operation (years since January 1, 1995)

\section{Procedure Variables}

Surgery type. Coronary artery bypass grafting, mitral valve repair, mitral valve replacement, aortic valve repair, aortic valve replacement

Procedure. Internal thoracic artery graft used 


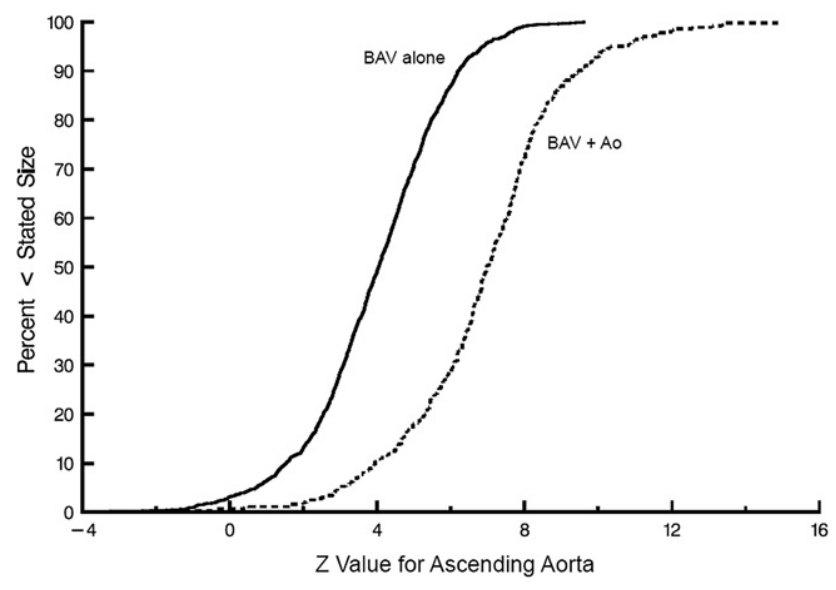

FIGURE E1. Cumulative distribution of ascending aorta size at bicuspid aortic valve surgery: $\mathrm{Z}$ value. Vertical axis represents nonparametric percentile; thus, the value for ascending aorta diameter at the $50 \%$ point on the vertical axis is the median value (50th percentile), the values at $10 \%$ and $90 \%$ are the 10th and 90th percentiles, and so forth. $B A V$, Bicuspid aortic valve surgery alone; $B A V+A o$, bicuspid aortic valve surgery and ascending aorta repair.
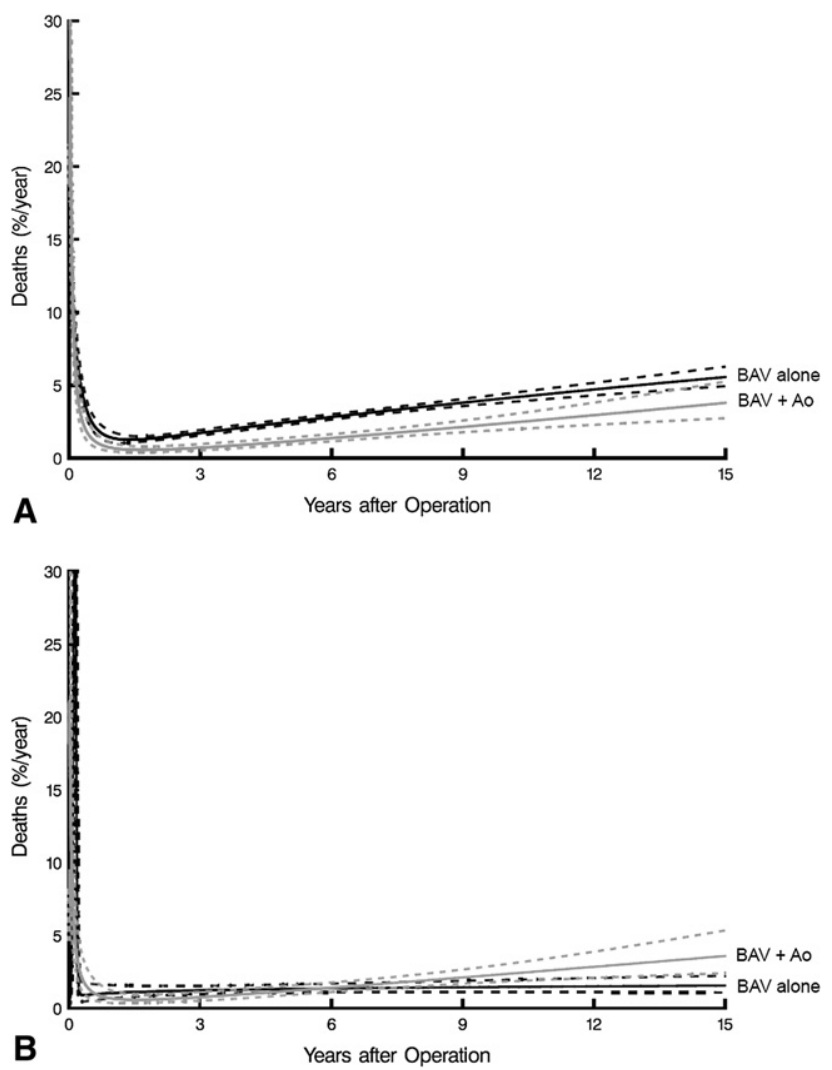

FIGURE E2. Instantaneous risk of death (hazard function) enclosed within $68 \%$ confidence limits. A, Whole cohort. B, Matched cohort. $B A V$, Bicuspid aortic valve surgery alone; $B A V+A o$, bicuspid aortic valve surgery and ascending aorta repair. 
TABLE E1. Patient characteristics, procedure details, and length of stay information for patients undergoing bicuspid aortic valve surgery with or without ascending aorta repair

\begin{tabular}{|c|c|c|c|c|c|}
\hline \multirow[b]{2}{*}{ Variable } & \multicolumn{2}{|c|}{ BAV alone $(n=1449)$} & \multicolumn{2}{|c|}{ BAV plus aorta $(n=361)$} & \multirow[b]{2}{*}{$\boldsymbol{P}$} \\
\hline & $\mathbf{N}^{*}$ & Value & $\mathbf{N}^{*}$ & Value & \\
\hline \multicolumn{6}{|l|}{ Demographic data } \\
\hline Age $(y$, mean \pm SD $)$ & 1449 & $56 \pm 15$ & 361 & $54 \pm 14$ & .001 \\
\hline Female (no.) & 1449 & $353(24 \%)$ & 361 & $66(18 \%)$ & .01 \\
\hline Height $(\mathrm{cm}$, mean $\pm \mathrm{SD})$ & 1445 & $173 \pm 10$ & 361 & $176 \pm 10$ & $<.0001$ \\
\hline Body surface area $\left(\mathrm{m}^{2}\right.$, mean $\left.\pm \mathrm{SD}\right)$ & 1445 & $2.01 \pm 0.25$ & 361 & $2.1 \pm 0.24$ & .002 \\
\hline \multicolumn{6}{|l|}{ Clinical acuity } \\
\hline New York Heart Association functional class (no.) & 1449 & & 361 & & $<.0001$ \\
\hline I & & $242(17 \%)$ & & $105(29 \%)$ & \\
\hline II & & $853(59 \%)$ & & $191(53 \%)$ & \\
\hline III & & $252(17 \%)$ & & $49(14 \%)$ & \\
\hline IV & & $102(7.0 \%)$ & & $16(4.4 \%)$ & \\
\hline Emergency operation (no.) & 1449 & $13(0.9 \%)$ & 361 & $13(3.6 \%)$ & .0001 \\
\hline \multicolumn{6}{|l|}{ Cardiac comorbidity } \\
\hline AV regurgitation grade (no.) & 1416 & & 356 & & $<.0001$ \\
\hline None & & $328(23 \%)$ & & $48(13 \%)$ & \\
\hline Mild & & $258(18 \%)$ & & $41(12 \%)$ & \\
\hline Moderate & & $224(16 \%)$ & & $61(17 \%)$ & \\
\hline Moderately severe & & $174(12 \%)$ & & $71(20 \%)$ & \\
\hline Severe & & $432(30 \%)$ & & $135(38 \%)$ & \\
\hline AV stenosis grade (no.) & 1331 & & 350 & & $<.0001$ \\
\hline None & & $369(28 \%)$ & & $157(45 \%)$ & \\
\hline Mild & & $33(2.5 \%)$ & & $15(4.3 \%)$ & \\
\hline Mild to moderate & & $6(0.45 \%)$ & & $2(0.57 \%)$ & \\
\hline Moderate & & $60(4.5 \%)$ & & $28(8.0 \%)$ & \\
\hline Moderately severe & & $67(5.03 \%)$ & & $23(6.6 \%)$ & \\
\hline Severe & & $796(60 \%)$ & & $125(36 \%)$ & \\
\hline Previous cardiac operation (no.) & 1449 & $174(12 \%)$ & 361 & $47(13 \%)$ & 6 \\
\hline \multicolumn{6}{|l|}{ Aortic disease (no.) } \\
\hline Preoperative diagnosis of aortic aneurysm & 1449 & $27(1.9 \%)$ & 361 & $239(66 \%)$ & $<.0001$ \\
\hline Marfan syndrome & 1449 & $2(0.14 \%)$ & 361 & $8(2.2 \%)$ & $<.0001$ \\
\hline Dilated aorta & 1449 & $510(35 \%)$ & 361 & $277(77 \%)$ & $<.0001$ \\
\hline Aortic dissection & 1449 & $2(0.14 \%)$ & 361 & $24(6.6 \%)$ & $<.0001$ \\
\hline \multicolumn{6}{|l|}{ Noncardiac comorbidity } \\
\hline Smoking (no.) & 1428 & $749(52 \%)$ & 352 & $177(50 \%)$ & .5 \\
\hline Peripheral arterial disease (no.) & 1449 & $329(23 \%)$ & 361 & $62(17 \%)$ & .02 \\
\hline Carotid artery disease (no.) & 1449 & $295(20 \%)$ & 361 & $54(15 \%)$ & .02 \\
\hline Chronic obstructive pulmonary disease (no.) & 1133 & $232(20 \%)$ & 327 & $51(16 \%)$ & .05 \\
\hline Treated diabetes (no.) & 1391 & $127(9.1 \%)$ & 352 & $26(7.4 \%)$ & .3 \\
\hline Renal disease (no.) & 1449 & $44(3.04 \%)$ & 361 & $6(1.7 \%)$ & .2 \\
\hline Creatinine $(\mathrm{mg} / \mathrm{dL}$, mean $\pm \mathrm{SD})$ & 1406 & $1.1 \pm 0.69$ & 354 & $1.1 \pm 1.05$ & .1 \\
\hline \multicolumn{6}{|l|}{ Procedure } \\
\hline Hemiarch (no.) & 1449 & $1(0.07 \%)$ & 361 & $32(8.9 \%)$ & $<.0001$ \\
\hline $\operatorname{Arch}($ no.) & 1449 & $0(0 \%)$ & 361 & $10(2.8 \%)$ & $<.0001$ \\
\hline AV repair (no.) & 1449 & $206(14 \%)$ & 361 & $39(11 \%)$ & .09 \\
\hline AV replacement (no.) & 1449 & $1243(86 \%)$ & 361 & $322(89 \%)$ & .09 \\
\hline Mechanical valve & & $200(16 \%)$ & & $68(21 \%)$ & .03 \\
\hline Biologic valve & & $1004(81 \%)$ & & $250(78 \%)$ & .2 \\
\hline Unknown & & $39(3 \%)$ & & $4(1.2 \%)$ & .08 \\
\hline Mitral valve repair (no.) & 1449 & $102(7.04 \%)$ & 361 & $17(4.7 \%)$ & .1 \\
\hline Coronary artery bypass grafting (no.) & 1449 & $397(27 \%)$ & 361 & $76(21 \%)$ & .01 \\
\hline Myocardial ischemic time (min, mean $\pm \mathrm{SD})$ & 1447 & $74 \pm 34$ & 361 & $90 \pm 35$ & $<.0001$ \\
\hline Cardiopulmonary bypass time (min, mean $\pm \mathrm{SD}$ ) & 1448 & $98 \pm 45$ & 361 & $119 \pm 49$ & $<.0001$ \\
\hline
\end{tabular}


TABLE E1. Continued

\begin{tabular}{|c|c|c|c|c|c|}
\hline \multirow[b]{2}{*}{ Variable } & \multicolumn{2}{|c|}{ BAV alone $(n=1449)$} & \multicolumn{2}{|c|}{ BAV plus aorta $(n=361)$} & \multirow[b]{2}{*}{$\boldsymbol{P}$} \\
\hline & $\mathbf{N}^{*}$ & Value & $\mathbf{N}^{*}$ & Value & \\
\hline \multicolumn{6}{|l|}{ Length of stay $(\mathrm{d} \dagger)$} \\
\hline Intensive care unit & 1446 & $1 / 1 / 3$ & 361 & $1 / 1 / 3$ & .05 \\
\hline Postoperative & 1449 & $4 / 6 / 9$ & 361 & $5 / 6 / 9.9$ & .004 \\
\hline Total & 1449 & $4 / 6 / 13$ & 361 & $5 / 7 / 12$ & .1 \\
\hline
\end{tabular}

$B A V$, Bicuspid aortic valve; $A V$, aortic valve. *Patients with data available. †Data shown as 15 th, 50th, and 85 th percentiles.

TABLE E2. Ascending aorta size at time of bicuspid aortic valve surgery with or without ascending aorta repair

\begin{tabular}{|c|c|c|c|c|c|}
\hline \multirow[b]{2}{*}{ Variable } & \multicolumn{2}{|c|}{ BAV alone $(n=1449)$} & \multicolumn{2}{|c|}{ BAV plus aorta $(n=361)$} & \multirow[b]{2}{*}{$\boldsymbol{P}$} \\
\hline & Mean \pm SD & 15th/50th/85th Percentiles & Mean \pm SD & 15th/50th/85th Percentiles & \\
\hline Diameter $(\mathrm{cm})$ & $3.6 \pm 0.59$ & $3 / 3.6 / 4.2$ & $4.8 \pm 0.94$ & $3.9 / 4.8 / 5.6$ & $<.0001$ \\
\hline Diameter $/$ height $(\mathrm{cm} / \mathrm{m})^{*}$ & $2.1 \pm 0.34$ & $1.76 / 2.08 / 2.43$ & $2.7 \pm 0.54$ & $2.18 / 2.71 / 3.19$ & $<.0001$ \\
\hline Diameter/body surface area $\left(\mathrm{cm} / \mathrm{m}^{2}\right)^{*}$ & $1.82 \pm 0.33$ & $1.49 / 1.8 / 2.16$ & $2.4 \pm 0.52$ & $1.84 / 2.3 / 2.8$ & $<.0001$ \\
\hline Area $\left(\mathrm{cm}^{2}\right)$ & $10 \pm 3.4$ & $7.1 / 10 / 14$ & $19 \pm 7.6$ & $12 / 18 / 25$ & $<.0001$ \\
\hline Area/height $\left(\mathrm{cm}^{2} / \mathrm{m}\right)^{*}$ & $6.1 \pm 1.96$ & $4.2 / 5.8 / 8$ & $10 \pm 4.4$ & $6.8 / 10 / 14$ & $<.0001$ \\
\hline Area/body mass index $\left(\mathrm{cm}^{2}\right)^{*}$ & $0.39 \pm 0.14$ & $0.26 / 0.38 / 0.53$ & $0.69 \pm 0.3$ & 0.43/0.65/0.94 & $<.0001$ \\
\hline Area/body surface area $\left(\mathrm{cm}^{2} / \mathrm{m}^{2}\right)$ & $5.3 \pm 1.7$ & $3.6 / 5.1 / 7$ & $9.1 \pm 3.9$ & $5.8 / 8.6 / 12$ & $<.0001$ \\
\hline Z value* & $4.0 \pm 1.88$ & $2.2 / 4.04 / 5.8$ & $6.9 \pm 2.2$ & $4.7 / 7.0 / 8.8$ & $<.0001$ \\
\hline
\end{tabular}

$\mathrm{Z}$ value represents number of SDs by which aortic diameter deviated from mean expected normal diameter for patient's body surface area. $B A V$, Bicuspid aortic valve. *Data available for 1445 patients.

TABLE E3. Mortality and morbidity for bicuspid aortic valve surgery with or without ascending aorta repair

\begin{tabular}{|c|c|c|c|c|c|}
\hline \multirow[b]{2}{*}{ Variable } & \multicolumn{2}{|c|}{$\begin{array}{l}\text { BAV alone } \\
(\mathrm{n}=1449)\end{array}$} & \multicolumn{2}{|c|}{$\begin{array}{c}\text { BAV plus aorta } \\
\quad(\mathbf{n}=\mathbf{3 6 1})\end{array}$} & \multirow[b]{2}{*}{$\boldsymbol{P}$} \\
\hline & No. & $(\%)$ & No. & $(\%)$ & \\
\hline In-hospital death & 18 & $(1.2)^{*}$ & 4 & $(1.1) \dagger$ & $>.9$ \\
\hline \multicolumn{6}{|l|}{ In-hospital complications } \\
\hline Stroke & 19 & (1.3) & 6 & (1.7) & .6 \\
\hline $\begin{array}{l}\text { Return to operating room } \\
\text { for bleeding }\end{array}$ & 75 & $(5.2)$ & 21 & $(5.8)$ & 6 \\
\hline Myocardial infarction & 8 & $(0.55)$ & 2 & $(0.55)$ & $>.9$ \\
\hline Renal failure & 12 & $(0.83)$ & 2 & $(0.55)$ & $>.9$ \\
\hline Prolonged ventilation & 62 & (4.3) & 15 & $(4.2)$ & .9 \\
\hline Septicemia or sepsis & 31 & (2.1) & 5 & (1.4) & .4 \\
\hline
\end{tabular}

$B A V$, Bicuspid aortic valve. $* 68 \%$ confidence limits $0.95 \%$ to $1.6 \%$. $\dagger 68 \%$ confidence limits $0.58 \%$ to $2.0 \%$.
TABLE E4. Influence of aortic procedure and diameter on death and stroke

\begin{tabular}{lcc}
\hline \multicolumn{1}{c}{ Variable } & Estimate \pm SE & $\boldsymbol{P}$ \\
\hline In-hospital death & & \\
$\quad$ Ascending aortia surgery & $0.47 \pm 0.72$ & .5 \\
Ascending aortia diameter* & $4.4 \pm 2.6$ & .1 \\
Propensity score & $-0.59 \pm 1.3$ & .7 \\
Intercept & $-5.1 \pm 0.66$ & \\
In-hospital stroke & & \\
Ascending aortia surgery & $0.27 \pm 0.66$ & .7 \\
Ascending aortia diameter $\dagger$ & $0.23 \pm 0.81$ & .8 \\
Propensity score & $-0.32 \pm 1.3$ & .8 \\
Intercept & $-4.7 \pm 1.4$ & \\
\hline
\end{tabular}

SE, Standard error. *(Height/area of ascending aorta), inverse transformation. Ascending aortia area normalized by patient height. $\dagger \mathrm{Ln}$ (area of ascending aorta/height), logarithmic transformation. Ascending aortia area normalized by patient height. 